\title{
Loop-mediated isothermal amplification (LAMP) assays for detection of Theileria parva infections targeting the PIM and p150 genes
}

\author{
Oriel M.M. Thekisoe ${ }^{\mathrm{a}}$, Natasha E. Rambritch ${ }^{\mathrm{b}, \mathrm{c}}$, Ryo Nakao ${ }^{\mathrm{e}}$, Raoul S. Bazie ${ }^{\mathrm{a}}$, Peter Mbati ${ }^{\mathrm{b}}$, \\ Boniface Namangala ${ }^{\mathrm{d}}$, Imna Malele ${ }^{\mathrm{i}}$, Robert A. Skilton ${ }^{\mathrm{f}}$, Frans Jongejan ${ }^{\text {g.h }}$, Chihiro Sugimoto ${ }^{\mathrm{e}}$, \\ Shin-Ichiro Kawazu ${ }^{a}$, Noboru Inoue ${ }^{a, *}$ \\ ${ }^{a}$ National Research Center for Protozoan Diseases, Obihiro University of Agriculture and Veterinary Medicine, Obihiro, Hokkaido 080-8555, Japan \\ ${ }^{\mathrm{b}}$ Parasitology Research Program, University of the Free State, Qwaqwa Campus, Private Bag X13, Phuthaditjhaba 9866, South Africa \\ 'ARC-Onderstepoort Veterinary Institute, Onderstepoort 0110, South Africa \\ ${ }^{\mathrm{d}}$ School of Veterinary Medicine, University of Zambia, P.O. Box 32379, Lusaka, Zambia \\ ${ }^{\mathrm{e}}$ Research Center for Zoonosis Control, Hokkaido University, Sapporo, Hokkaido 060-0818, Japan \\ ${ }^{\mathrm{f}}$ Biosciences Eastern and Central Africa (BecA), International Livestock Research Institute (ILRI), P.O. Box 30709, Nairobi 00100, Kenya

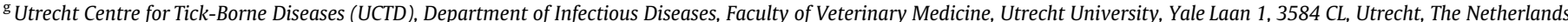 \\ ${ }^{\mathrm{h}}$ Department of Veterinary Tropical Diseases, Faculty of Veterinary Sciences, University of Pretoria, Onderstepoort 0110, South Africa \\ ${ }^{\mathrm{i}}$ Tsetse and Trypanosomiasis Research Institute (TTRI), Majani Mapana, Off Korongwe Road, P.O. Box 1026 Tanga, Tanzania
}

\section{A R T I C L E I N F O}

\section{Article history:}

Received 27 April 2009

Received in revised form 3 July 2009

Accepted 7 July 2009

Available online $\mathrm{xxxx}$

\section{Keywords:}

Theileria parva

LAMP

Buffalo

Cattle

Diagnosis

\begin{abstract}
A B S T R A C T
We have developed two loop-mediated isothermal amplification (LAMP) assays for the detection of Theileria parva, the causative agent of East Coast fever (ECF), an economically important cattle disease in eastern, central and southern Africa. These assays target the polymorphic immunodominant molecule (PIM) and p150 LAMP genes. The primer set for each gene target consists of six primers, and each set recognises eight distinct regions on the target gene to give highly specific detection of $T$. parva. The detection limit of each primer set is $1 \mathrm{fg}$, which is equivalent to one copy of the PIM and p150 T. parva genes. These PIM and p150 LAMP primer sets amplify DNA of $T$. parva isolates from cattle and buffalo from different countries including Kenya, South Africa, Tanzania, Rwanda, Uganda and Burundi, indicating their ability to detect $T$. parva from different countries. With the advantages of simplicity, rapidity and cost effectiveness, these LAMP assays are good candidates for molecular epidemiology studies and for monitoring control programs in ECF-endemic, resource poor countries.
\end{abstract}

(c) 2009 Australian Society for Parasitology Inc. Published by Elsevier Ltd. All rights reserved.

\section{Introduction}

Theileria parva is the causative agent of East Coast fever (ECF), a rapidly fatal lymphoproliferative disease of cattle in eastern, central and southern Africa. ECF is found only in areas where its tick vectors occur, particularly Rhipicephalus appendiculatus and Rhipicephalus zambeziensis. For susceptible cattle in an epidemic situation the rate of mortality can reach 95\% (Medley et al., 1993). The main wildlife host of T. parva is the African Cape buffalo (Syncerus caffer) in which the parasite does not normally cause disease. A carrier state of T. parva, defined as the persistence of a tick transmissible infection, is common amongst naturally recovered host animals, both cattle and African buffalo (Dolan, 1999; Bishop et al., 2004).

\footnotetext{
* Corresponding author. Address: National Research Center for Protozoan Diseases, Obihiro University of Agriculture and Veterinary Medicine, Inada-cho, Obihiro, Hokkaido 080-8555, Japan. Tel.: +81 15549 5647; fax: +81 155495643.

E-mail address: ircpmi@obihiro.ac.jp (N. Inoue).
}

Field diagnosis is normally achieved by observing clinical signs in infected animals: ECF is indicated by fever, enlarged lymph nodes and is associated with tick vector infestation. In addition, an acute disease with high mortality on farms without effective tick control may also indicate ECF. The disease can be confirmed by finding Theileria parasites in Giemsa-stained blood smears and lymph node needle biopsy smears (OIE, 2008). In addition there have been numerous diagnostic assays developed for the detection of $T$. parva infections, mainly for use in research, including vaccine and epidemiological studies. These include serological assays such as the indirect fluorescence antibody test (IFAT) and ELISA (Billiouw et al., 2005; Katende et al., 1998), which have been important tools for classifying the epidemiological states of ECF. The limitations of IFAT, an assay which uses whole schizont material as antigen, have included poor sensitivity and specificity. An ELISA that uses a defined recombinant $T$. parva antigen appears to perform better, with good sensitivity and specificity (Katende et al., 1998). However, serological assays are unable to differentiate between current and past infections due to the persistence of antibodies. 
Table 1

Theileria stock/isolate DNA used in this study.

\begin{tabular}{lllll}
\hline Species & Stock/isolate & Host & Country & Year \\
\hline Theileria parva & Muguga & Cattle & Kenya & ND \\
T. parva & Onderstepoort (UCTD) & Cattle & South Africa & ND \\
T. parva & Hluhluwe & Buffalo & South Africa & 2005 \\
T. parva & Pugu I Dar es Salaam & Cattle & Tanzania & 1978 \\
T. parva & Nyakizu & Cattle & Rwanda & 1979 \\
T. parva & Serengeti & Cattle & Tanzania & 1978 \\
T. parva & Entebbe & Cattle & Uganda & 1980 \\
T. parva & Katumba & Cattle & Burundi & 1981 \\
Theileria annulata & Tova & Cattle & Israel & 1974 \\
Theileria mutans & Intona & Cattle & Kenya & 1990 \\
Theileria taurotragi & R6 & Cattle & Kenya & 1992 \\
Theileria orientalis & Chitose & Cattle & Japan & ND \\
\hline
\end{tabular}

ND, no data.

PCR diagnostic assays have been developed for the sensitive and specific detection of T. parva, including the detection of very low levels of the parasite in carrier animals (Bishop et al., 1992; Gubbels et al., 1999; Skilton et al., 2002). These assays are not in widespread use in the resource poor countries where ECF occurs due to the relatively complex nature of the assays, and the need for expensive equipment and well-trained personnel (Kuboki et al. 2003; Poon et al. 2006).

Loop-mediated isothermal amplification (LAMP) is a simple technique which amplifies DNA with high sensitivity and rapidity under isothermal conditions (Notomi et al., 2000). LAMP products can easily be detected by the naked eye due to the formation of magnesium pyrophosphate, a white turbid by-product of DNA amplification which accumulates as the reaction progresses (Mori et al., 2001). Furthermore LAMP products can be detected by direct fluorescence by adding Loopamp ${ }^{\circledR}$ fluorescent detection reagent (FD) (Eiken Chemical Co. Ltd., Japan) at the start of the reaction (Tomita et al., 2008). Other fluorescent dyes such as ethidium bromide, SYBR green and Evagreen have also been used for visualisation of LAMP products under UV light (Qiao et al., 2007). LAMP can amplify different forms of templates including purified genomic DNA, heat-treated blood and blood dried on filter papers (Kuboki et al., 2003; Poon et al., 2006). In addition, we have recently reported that LAMP reagents are relatively stable even when stored at 25 and $37{ }^{\circ} \mathrm{C}$, which supports the use of LAMP in field conditions and resource poor laboratories (Thekisoe et al., 2009).

Salih et al. (2008) have reported a specific LAMP assay for diagnosis of tropical theileriosis caused by Theileria annulata. We previously developed a LAMP assay based on heat shock protein 70 (HSP70) which amplifies major bovine Theileria species but is not specific for T. parva (Thekisoe et al., 2007). In this study we have developed two LAMP assays for specific detection of $T$. parva targeting the polymorphic immunodominant molecule (PIM) and p150 genes.

\section{Materials and methods}

\subsection{Parasite DNA and field samples}

Table 1 shows Theileria stocks or isolates used in this study. Theileria parva (Muguga) DNA was extracted from in vitro cultured schizont-infected lymphocytes. DNA of T. annulata, Theileria mutans and Theileria taurotragi was obtained from the International Livestock Research Institute (ILRI), Kenya. DNA of other T. parva isolates was obtained from Utrecht Centre for Tick-borne Diseases (UCTD), Utrecht University, Netherlands. The Theileria orientalis (Chitose strain) DNA was extracted from blood of an infected cattle in Chitose, Hokkaido, Japan. This study also used DNA from other protozoan parasites to check the specificity of the LAMP assays, namely Babesia bovis (Texas strain); Babesia bigemina (Argentina strain); Trypanosoma brucei brucei (GUTat 3.1) and DNA extracted from blood of an uninfected cattle from the National Research Center for Protozoan Diseases, Obihiro University of Agriculture and Veterinary Medicine, Japan. The 99 buffalo DNA samples from blood collected from various game parks in the South Africa, were supplied by the ARC-Onderstepoort Veterinary Institute. The buffalo samples were used as controls as data on their T. parva infection status was known prior to the commencement of the current study. A further 150 DNA samples were extracted from blood collected from cattle in Robanda village near Serengeti National Park in Tanzania.

\subsection{DNA extraction}

DNAs from T. parva-infected lymophocyte cell cultures and uninfected cattle blood as well as cattle samples from Tanzania were extracted by the phenol-chloroform method (Sambrook and Russell, 2001). Briefly, the extraction buffer (10 mM Tris- $\mathrm{HCl}$ [pH 8.0], $10 \mathrm{mM}$ EDTA, $1 \%$ sodium dodecyl sulphate) and $100 \mu \mathrm{g} /$ $\mathrm{ml}$ proteinase $\mathrm{K}$ were added to the samples and incubated overnight at $55^{\circ} \mathrm{C}$. DNA was extracted with phenol-chloroform-isoamyl alcohol (25:24:1) and precipitated with isopropanol. DNA was dissolved in $250 \mu \mathrm{l}$ of TE buffer ( $10 \mathrm{mM}$ Tris-HCl, $1 \mathrm{mM}$ EDTA, pH8.0). The genomic DNA of field-derived buffalo blood samples was extracted using a MagNa Pure LC DNA isolation kit according to the manufacturer's procedures (Roche, Mannheim, Germany).

\subsection{Preparation of plasmid DNA}

The T. parva PIM and p150 genes of the Muguga stock were amplified by PCR using the F3 and B3 primers listed in Table 2. The PCR products were purified by QIAquick gel extraction kit according to the manufacturer's instructions (Qiagen, USA). Thereafter the PCR products were ligated into vector using the T-Vector

Table 2

The p150 and polymorphic immunodominant molecule (PIM) loop-mediated isothermal amplification (LAMP) primer sequences used in this study.

\begin{tabular}{|c|c|c|c|c|}
\hline Target gene & Accession No. & Target size & Primer name & Sequence $\left(5^{\prime}-3^{\prime}\right)$ \\
\hline \multirow[t]{2}{*}{ p150 } & $\underline{\mathbf{L} 47230}$ & 198 bp & FIP & GCGGACGAGATCATTAACTGTGATCCTTCTTCTTGATTGCGTA \\
\hline & & & $\begin{array}{l}\text { BIP } \\
\text { F3 } \\
\text { B3 } \\
\text { LF } \\
\text { LB }\end{array}$ & $\begin{array}{l}\text { GACACTCGGCGATGGTCTTGGGGCAAGGTAATTAATCTTTCA } \\
\text { TTATCTGTTGGCCTTAGCA } \\
\text { CAATTTACCTCATTTGCACTG } \\
\text { CAAGGAGTCACCCTCGTC } \\
\text { GTTTCTAAATGCTGCGTTCCTAAAG }\end{array}$ \\
\hline \multirow[t]{2}{*}{ PIM } & $\underline{\mathbf{L} 41833}$ & 192 bp & FIP & GGCACAAAGTGCAATCAAAAAGAGAAGAAGTTTCATTTTCGACTGT \\
\hline & & & $\begin{array}{l}\text { BIP } \\
\text { F3 } \\
\text { B3 } \\
\text { LF } \\
\text { LB }\end{array}$ & $\begin{array}{l}\text { GCATTGGACTTTTTGCTCATGCTCCTACGGAATAGCCCAAGA } \\
\text { GTTCTGAGAGCAAAGGCG } \\
\text { GGCTAACGAGGATAGTACGT } \\
\text { AGAGATGTGTCAAAAG } \\
\text { TTCAATGTTGGTGTATTCTTTGCCG }\end{array}$ \\
\hline
\end{tabular}

FIP, forward inner primer; BIP, backward inner primer; F3, forward outer primer; B3, backward outer primer; LF, loop forward primer; LB, loop backward primer. 


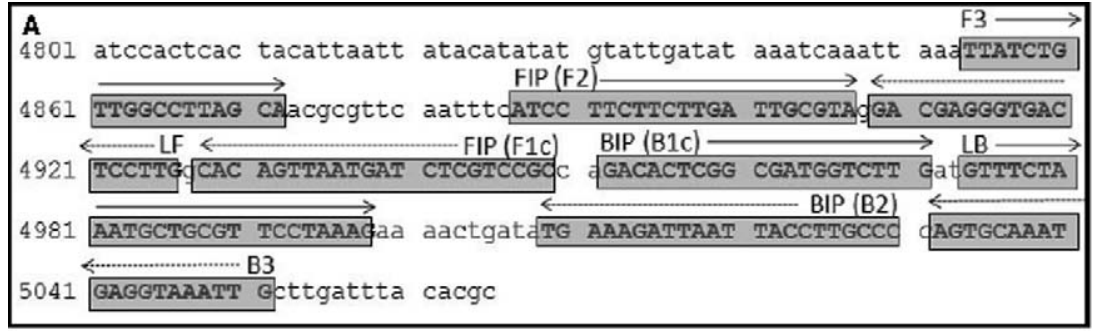

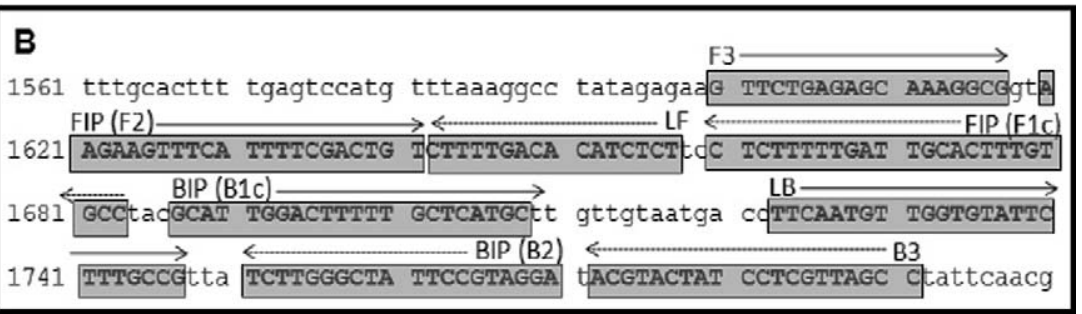

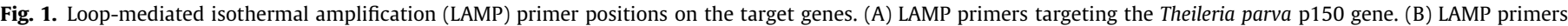

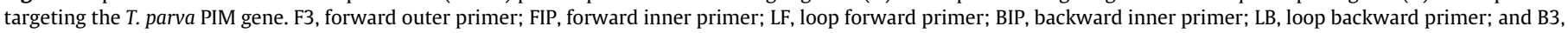
backward outer primer. The solid arrows indicate the sense primers and the dotted arrows indicate the antisense primers.
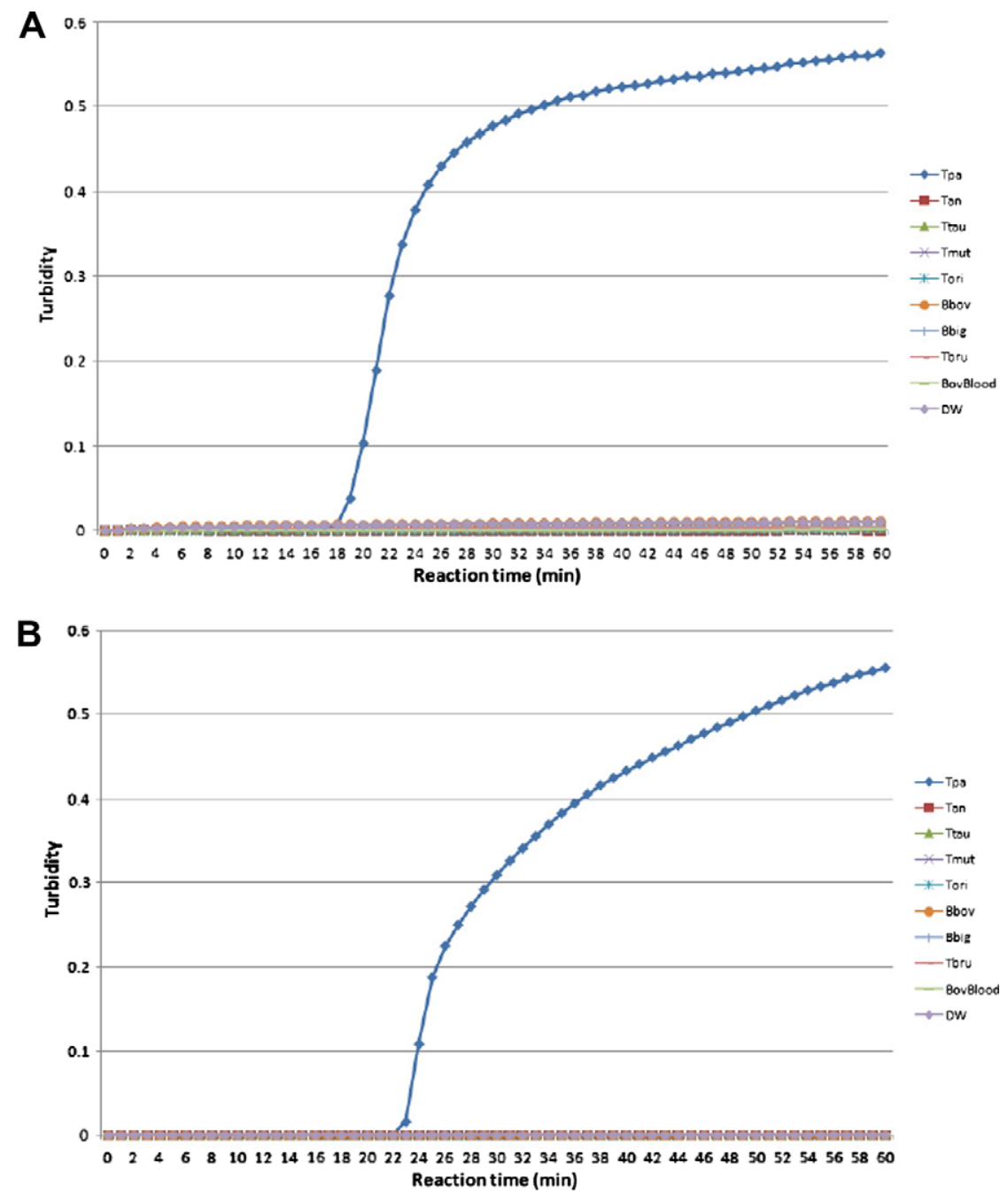

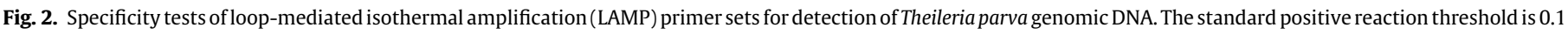

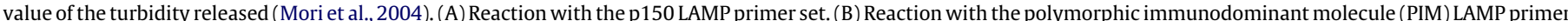

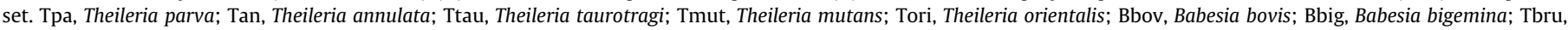
Trypanosoma brucei brucei; BovBlood, DNA extracted from uninfected cattle blood; DW, distilled water.

Please cite this article in press as: Thekisoe, O.M.M., et al. Loop-mediated isothermal amplification (LAMP) assays for detection of Theileria parva infections targeting the PIM and p150 genes. Int. J. Parasitol. (2009), doi:10.1016/j.ijpara.2009.07.004 
Topo ${ }^{\circledR}$ Cloning 5 min PCR cloning kit (Invitrogen, USA). The recombinant plasmids were transformed into Escherichia coli $\mathrm{DH} 5 \alpha$ and incubated for $12 \mathrm{~h}$ at $37^{\circ} \mathrm{C}$. The single colonies were cultivated in Luria-Bertani medium (LB) and plasmid DNA was purified using the Qiagen Midi kit (Qiagen, USA). Thereafter the concentration of plasmid DNA was quantified and used in sensitivity tests.

\subsection{LAMP}

The LAMP primer sets (Table 2) were designed from the PIM and p150 genes of T. parva (Muguga) using the Primer Explorer V4 Software (http://primerexplorer.jp/e/). Fig. 1A and B further show the primer positions on the target genes. LAMP reaction was conducted as described by Notomi et al. (2000) with minor modifications. For determination of optimal reaction temperatures of the newly designed LAMP primer sets, initial LAMP reactions were conducted at $60,61,62,63$ and $64^{\circ} \mathrm{C}$ for the p150 primer set because the average melting temperature $\left(T_{\mathrm{m}}\right)$ of the six primers was $62.9{ }^{\circ} \mathrm{C}$. For the PIM LAMP primer set reactions were conducted at $56,58,60,61$ and $62{ }^{\circ} \mathrm{C}$ because the average $T_{\mathrm{m}}$ of the six primers was $60.5^{\circ} \mathrm{C}$. The temperature in which the reaction would reach and cross the positive reaction threshold which is 0.1 of released turbidity (Mori et al., 2004) in a short period of time or faster than others was to be selected as the optimal reaction temperature (these reactions were done in five repetitions).
The LAMP reaction mixture with a total volume of $25 \mu \mathrm{l}$ contained: $12.5 \mu \mathrm{l}$ of $2 \times$ LAMP reaction buffer $(40 \mathrm{mM}$ Tris- $\mathrm{HCl}[\mathrm{pH}$ 8.8], $20 \mathrm{mM} \mathrm{KCl}, 16 \mathrm{mM} \mathrm{MgSO}_{4}, 20 \mathrm{mM}\left(\mathrm{NH}_{4}\right)_{2} \mathrm{SO}_{4}, 0.2 \%$ Tween 20, $1.6 \mathrm{M}$ Betaine, $2.8 \mathrm{mM}$ of each dNTP), $1 \mu \mathrm{l}$ ( 8 units) of Bst DNA polymerase, $2.6 \mu \mathrm{l}$ primer mix (forward inner primer (FIP) and backward inner primer (BIP) at 40 pmol each, forward outer primer (F3) and forward outer primer (B3) at 10 pmol each, and loop forward primer (LoopF) and loop backward primer (loopB) at $20 \mathrm{pmol}$ each), $3 \mu \mathrm{l}$ of template DNA and $5.9 \mu \mathrm{l}$ of double distilled water. For the reactions where $1 \mu \mathrm{l}$ of FD was added, the volume of distilled water was reduced by $1 \mu$ l. All LAMP reactions were carried out for $60 \mathrm{~min}$ in a real-time turbidimeter (Loopamp LA200, Teramics, Japan) with a standard positive reaction threshold of 0.1 of the turbidity released (Mori et al., 2004). The LAMP products were also electrophoresed in $2 \%$ agarose gel, stained with ethidium bromide and visualised under UV light.

\section{5. $P C R$}

The PCR reactions were conducted using the F3 and B3 primers of the p150 and PIM LAMP primer sets as shown in Table 2. The PCR reaction mixture contained $10 \times$ PCR buffer $(200 \mathrm{mM}$ Tris-

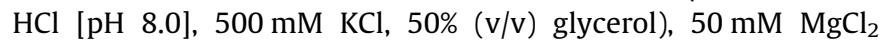
$10 \mathrm{mM}$ of dNTP mixture, $5 \mathrm{pmol}$ of each primer, $5 \mathrm{U} / \mu \mathrm{l}$ of $\mathrm{Taq}$ DNA polymerase (Invitrogen, USA) and $3 \mu \mathrm{l}$ of DNA in a final volume of $50 \mu$ l. The reaction mixture was heated at $94{ }^{\circ} \mathrm{C}$ for

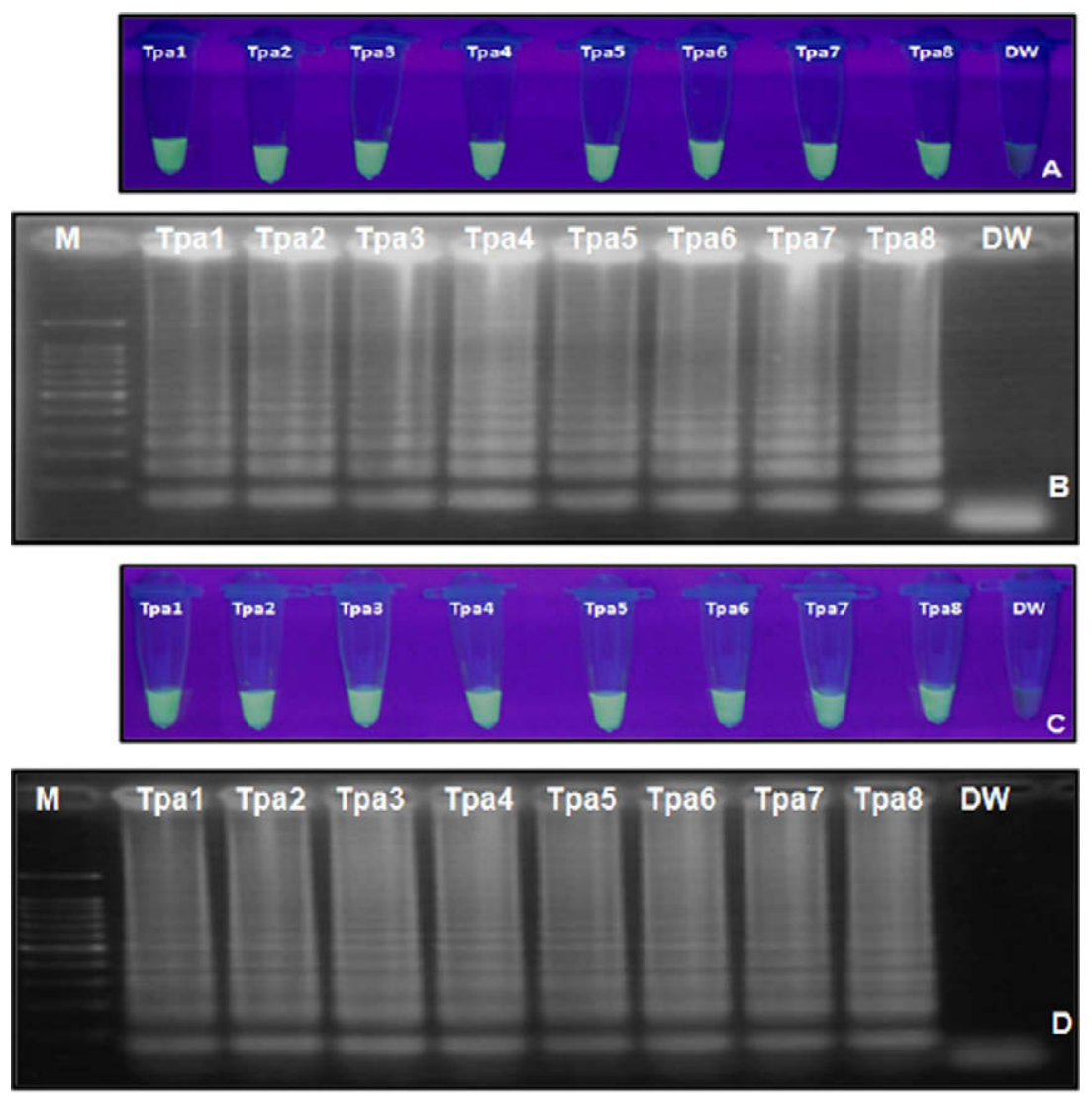

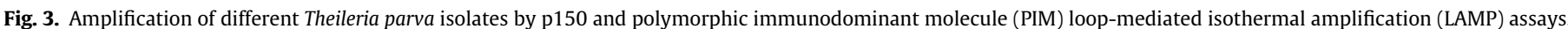

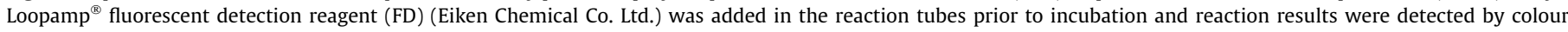

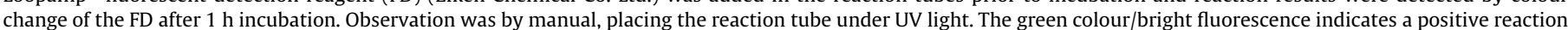

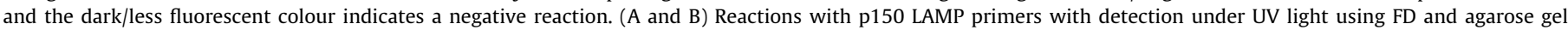

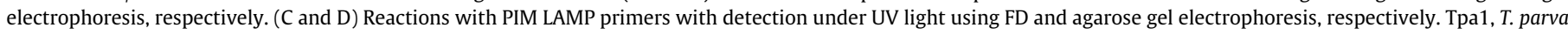

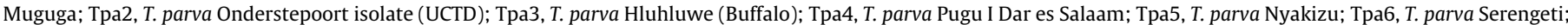

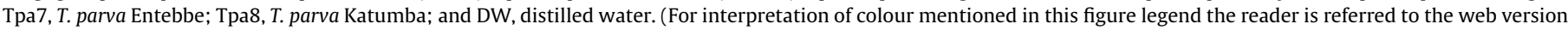
of the article.) 
$10 \mathrm{~min}$ (denaturation step) and subjected to 40 cycles at $94{ }^{\circ} \mathrm{C}$ for $45 \mathrm{~s}, 1 \mathrm{~min}$ at $58^{\circ} \mathrm{C}$, and $1 \mathrm{~min}$ at $72^{\circ} \mathrm{C}$ with a final extension at $72{ }^{\circ} \mathrm{C}$ for $7 \mathrm{~min}$. The PCR products were electrophoresed in 1.5\% agarose gel, stained with ethidium bromide and visualised under UV light.

\section{Results}

\subsection{Optimal temperature and specificity of LAMP primers}

The optimal temperature of the p150 LAMP primer set is $63^{\circ} \mathrm{C}$ and that of the PIM LAMP primer set is $60^{\circ} \mathrm{C}$. Despite these optimal reaction temperatures of the respective LAMP primer sets, amplification reactions were also achieved with temperatures below and above the optimal temperatures, although with a slightly slower threshold time for a positive reaction (data not shown). The PIM and p150 LAMP assays amplified only $T$. parva DNA whilst negative control DNA of other bovine Theileria species, bovine Babesia species, Trypanosoma, uninfected cattle blood and distilled water (non-DNA control) were not amplified (Fig. 2A and B). Furthermore, both PIM and p150 LAMP assays amplified DNA of T. parva isolates of cattle from Katumba (Burundi), Onderstepoort (South Africa), Pugu I Dar es Salaam (Tanzania), Nyakizu (Rwanda), Serengeti (Tanzania), Entebbe (Uganda) and a buffalo isolate from Hluhluwe (South Africa) (Fig. 3).

\subsection{Detection limit of LAMP}

The detection limit of both the PIM and p150 LAMP assays is $100 \mathrm{fg}$ as determined from serially diluted total DNA extracted from in vitro cultured $T$. parva (Muguga) schizont-infected lymphocytes (Fig. 4A and B). Furthermore, in serially diluted target gene fragments referred to as plasmid DNA (pDNA) in this study, the detection limit of both assays was as low as $1 \mathrm{fg}$ (Table 3 ). In
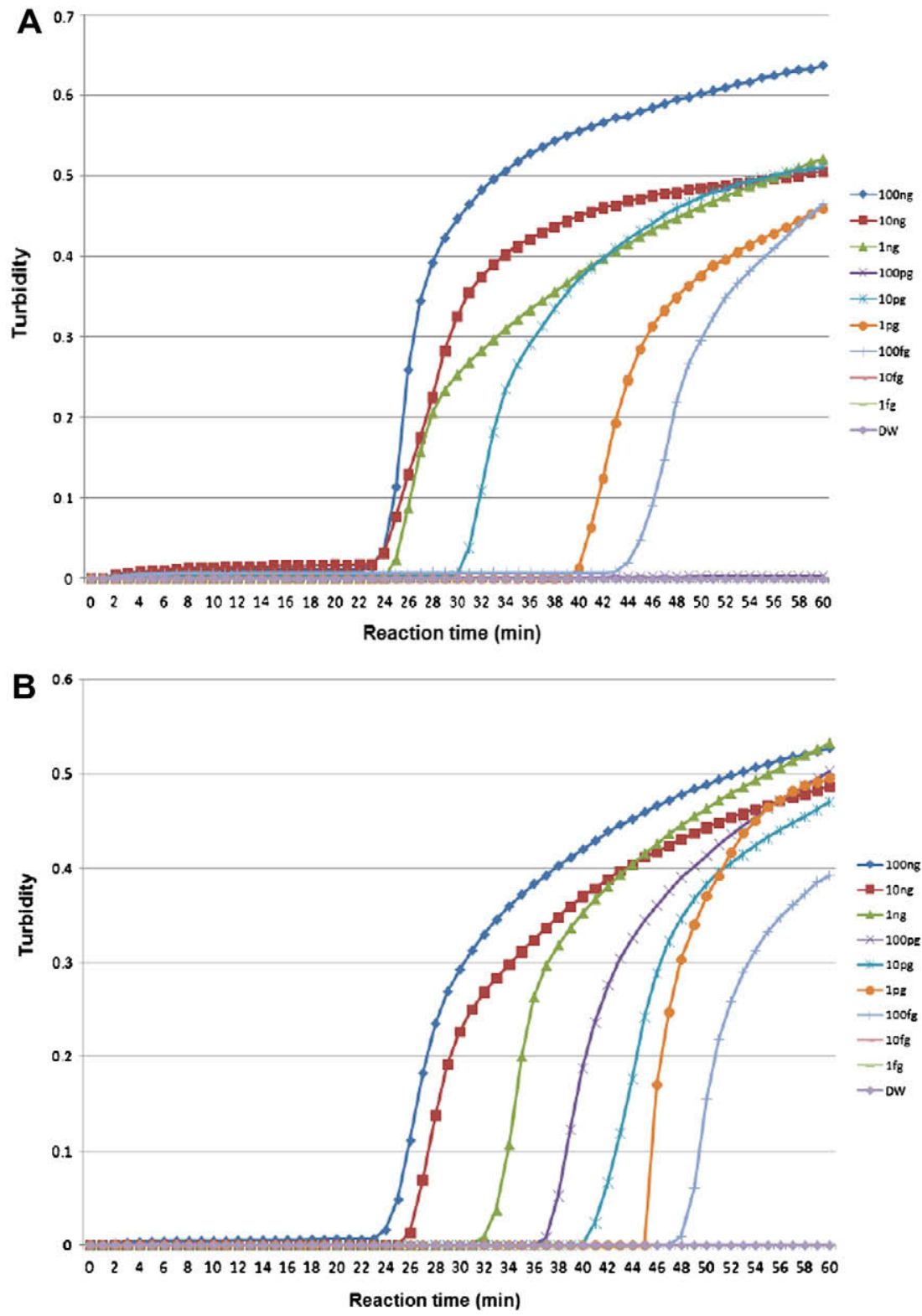

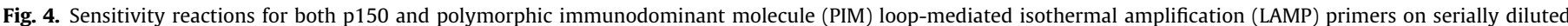

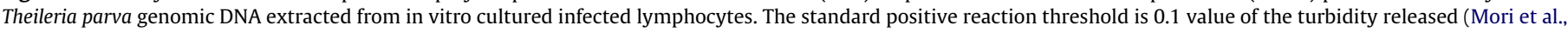
2004). (A) Reaction with the p150 LAMP primer set. (B) Reaction with the PIM LAMP primer set. 
addition to a real-time turbidimetry device which records the turbidity value versus time, we used the fluorescent detection reagent which enables detection of results by the naked eye (i.e. manually) or under UV illumination, and its detection results were consistent with those obtained from real-time LAMP turbidimetry (data not shown).

\subsection{Detection of T. parva infections from field-derived buffalo and cattle samples}

Out of 99 buffalo DNA samples from South Africa with previously confirmed Theileria infection status, 90 were positively amplified by both the PIM and p150 T. parva LAMP assays (Table 4). PCR with the F3 and B3 primers of both PIM and p150 genes gave identical results for these buffalo samples (Table 4). Out of 150 DNA samples collected from clinically healthy cattle in Robanda village of Tanzania, one sample $(0.6 \%)$ was positively detected for T. parva infection by both the PIM and p150 LAMP assays as well as the PIM and p150-PCR assays (Table 4). The PCR products from this single Tanzanian positive sample were directly sequenced and shown to be derived from T. parva PIM and p150 genes, confirming that the products were specific (data not shown).

\section{Discussion}

In this study we report on development of $T$. parva-specific LAMP assays based on the PIM and p150 genes. Both the PIM and p150 LAMP primer sets specifically amplified the $T$. parva DNA, whilst DNA of other protozoan parasites known to infect cattle and buffalo were not amplified. Serological tests with p150 and PIM recombinant antigens have shown high specificity when tested against other protozoa (Katende et al., 1998). Both the p150 and PIM genes are polymorphic within their repeat sequence regions between isolates (Toye et al., 1995; Skilton et al., 1998). However, it is known that the PIM gene also contains conserved regions present amongst many isolates from different countries (Toye et al., 1996). In agreement with that notion, this study has demonstrated that the LAMP primer sets designed from the gene sequences of $T$. parva (Muguga) which was originally isolated in

Table 3

Detection limit of the polymorphic immunodominant molecule (PIM) and p150 loopmediated isothermal amplification (LAMP) assays.

\begin{tabular}{lll}
\hline LAMP assay & Type of DNA & Detection limit $(\mathrm{fg})$ \\
\hline PIM & gDNA $^{\mathrm{a}}$ & 100 \\
PIM & pDNA $^{\mathrm{b}}$ & 1 \\
P150 & gDNA & 100 \\
P150 & pDNA & 1 \\
\hline
\end{tabular}

pDNA, plasmid DNA.

a Total genomic DNA (gDNA) extracted from schizont-infected lymphocytes.

b Target sequence cloned into plasmid culture vector.
Kenya, could also amplify DNA of T. parva isolates from South Africa, Tanzania, Rwanda, Uganda and Burundi, indicating geographical conservation of the sequences. Njiru et al. (2008) reported that purified trypanosome DNA $>200$ ng had an inhibitory effect on LAMP reaction as monitored in real-time, and showed very weak bands on the agarose gel. Similarly, in the current study one of the T. parva genomic DNA isolates was initially not amplified due to highly concentrated DNA, however after dilution to $\sim 100 \mathrm{ng}$ LAMP amplification was achieved. It is therefore advisable to ensure DNA is appropriately diluted after DNA extraction and to use at least a $100 \mathrm{ng}$ DNA template concentration as the maximum per reaction or two to three dilutions of extracted DNA.

The p150 and PIM LAMP primer sets amplified serially diluted $T$. parva DNA with high sensitivity whereby their detection limit was $100 \mathrm{fg}$ for serially diluted $T$. parva genomic DNA extracted from schizont-infected lymphocytes. Although we used a real-time turbidimeter device in the current study, we have further demonstrated that LAMP reaction products can be detected by use of Loopamp fluorescent detection reagent which is added in the reaction tube before incubation. This mode of detection gave similar results to real-time turbidimetry whereby it also indicated positive reactions for serially diluted genomic and plasmid DNAs down to $100 \mathrm{fg}$ and $1 \mathrm{fg}$, respectively.

African buffalo usually harbour T. parva parasites and act as reservoirs of infections for ticks and ultimately cattle (Dolan, 1999; Bishop et al., 2004) in domestic and wild animal interface areas (Grootenhuis and Olubayo, 1993). Archived total blood DNA samples from African Cape buffaloes in three provinces of the Republic of South Africa as well as DNA extracted from cattle in Robanda village of Tanzania were screened for $T$. parva infections with the p150 and PIM LAMP and PCR assays. Archived total blood DNA samples from buffaloes had previously confirmed positivity for $T$. parva (90 samples) or Theileria sp. (nine samples) by standard real-time PCR at the ARC-Onderstepoort Veterinary Institute. As a result $90 \%$ of the buffalo samples were $T$. parva positive when screened by both p150 and PIM LAMP primer sets. Identical results were obtained by PCR using the F3 and B3 primer pairs of the respective LAMP primer sets.

Primers designed from the p104 and p67 genes have been successfully used for PCR amplification and detection of $T$. parva infections (Skilton et al., 2002; Musoke et al., 2005). Prior to this study several LAMP primer sets were designed from the p67 and p104 genes of $T$. parva. Specific amplification of $T$. parva DNA with these p67 and p104 primers was also achieved, however LAMP reactions with the respective primers were slow or delayed for unknown reasons. As a result high sensitivity could not be achieved within 60 min of reaction time (data not shown). This observation brings to light the fact that performance of LAMP assays is also affected by the selected target sequence and its physical characteristics. Another important issue is that, since LAMP uses four to six primers, one has to take care that there is no significant difference in melting temperatures between the primers. In the case of the p104 and p67 primer sets (more than 10 LAMP primer sets designed in this

Table 4

Detection of Theileria parva infections by loop-mediated isothermal amplification (LAMP) from buffalo and cattle samples.

\begin{tabular}{|c|c|c|c|c|c|c|c|}
\hline Country & Province & Host & Total no of samples & P150 LAMP +ve $(\%)$ & PIM LAMP +ve (\%) & P150 PCR +ve (\%) & PIM PCR +ve (\%) \\
\hline \multirow[t]{3}{*}{ South Africa } & KwaZulu-Natal & Buffalo & 85 & $85(100)$ & $85(100)$ & $85(100)$ & $85(100)$ \\
\hline & Limpopo & Buffalo & 5 & $5(100)$ & $5(100)$ & $5(100)$ & $5(100)$ \\
\hline & Mpumalanga & Buffalo & $9^{b}$ & $0(0)$ & $0(0)$ & $0(0)$ & $0(0)$ \\
\hline Tanzania & Robanda & Cattle & 150 & $1(0.6)$ & $1(0.6)$ & $1(0.6)$ & $1(0.6)$ \\
\hline
\end{tabular}

PIM, polymorphic immunodominant molecule.

a Positive detection.

b The nine samples were positive for Theileria sp. buffalo by real-time PCR targeting the 18S rRNA (unpublished data). 
study), most of the primers had high $T_{\mathrm{m}}$ differences of more than $10^{\circ} \mathrm{C}$ between each of them. We therefore suspect that some of the primers would not melt at a single temperature used in the LAMP reaction. This could also be the reason why the reactions were slow or delayed.

The final amplified DNA products in a LAMP reaction are cauliflower-like structures with multiple loops formed by annealing between alternately inverted repeats of the target in the same strand which appear in a ladder-like pattern in agarose gel in contrast to a single band in PCR (Notomi et al., 2000). Furthermore, a LAMP byproduct called magnesium pyrophosphate released in a positive DNA amplification reaction (Mori et al., 2001) can be detected using FD (Eiken Chemical Co. Ltd., Japan) which is added prior to incubation of the reaction mixture. The FD contains calcein bound with manganese ion so as to remain quenched. When the reaction proceeds the manganese ion is deprived of calcein by the generated pyrophosphate which results in emission of fluorescence. The free calcein then binds with magnesium ion in the reaction mixture so that it strengthens the fluorescence emission (Tomita et al., 2008).

In conclusion, the current study has developed specific, sensitive and rapid LAMP assays for detection of T. parva infections targeting the p150 and PIM genes. These LAMP assays are rapid as shown by low concentrations of $T$. parva DNA being amplified within $60 \mathrm{~min}$. An additional advantage is that results can be observed in real-time when using a real-time turbidimetry device or manually immediately after the reaction using fluorescent detection dyes. There is still a need for further evaluation of these LAMP assays with more field samples representative of areas where T. parva is prevalent in Eastern, Central and Southern Africa.

\section{Acknowledgements}

The cattle owners in Robanda, Tanzania are gratefully acknowledged for their cooperation. We also thank all personnel who assisted in collection of field samples in South Africa and Tanzania. The first author was supported by a research grant fellowship from the Japanese Society for the Promotion of Science (JSPS) for young scientists. This study was also made possible by a Grant-in-aid made available to C.S., S.K. and N.I., and a National Research Foundation (South Africa) grant made available to P.M.

\section{References}

Billiouw, M., Brandt, J., Vercruysse, J., Speybroeck, N., Marcotty, T, Mulumba, M. Berkvens, D., 2005. Evaluation of the indirect fluorescent antibody test as a diagnostic tool for East Coast fever in eastern Zambia. Vet. Parasitol. 127, 189198.

Bishop, R., Sohanpal, B., Kariuki, D.P., Young, A.S., Nene, V., Baylis, H., Allsopp, B.A., Spooner, P.R., Dolan, T.T., Morzaria, S.P, 1992. Detection of a carrier state in Theileria parva-infected cattle by the polymerase chain reaction. Parasitology 104, 215-232.

Bishop, R., Musoke, A., Morzaria, S., Gardner, M., Nene, V., 2004. Theileria: intracellular protozoan parasites of wild and domestic ruminants transmitted by ixodid ticks. Parasitology 129, S271-S283.

Dolan, T.T., 1999. Dogmas and misunderstandings in East Coast fever. Trop. Med. Int. Health 4, A3-A11.

Grootenhuis, J.G., Olubayo, R.O., 1993. Disease research in the wildlife-livestock interface in Kenya. Vet. Q. 15, 55-59.
Gubbels, J.M., de Vos, A.P., van der Weide, M., Viseras, J., Schouls, L.M., de Vries, E., Jongejan, F., 1999. Simultaneous detection of bovine Theileria and Babesia species by reverse line blot hybridization. J. Clin. Microbiol. 37, 1782-1789.

Katende, J., Morzaria, S., Toye, P., Skilton, R., Nene, V., Nkonge, C., Musoke, A., 1998. An enzyme-linked immunosorbent assay for detection of Theileria parva antibodies in cattle using a recombinant polymorphic immunodominant molecule. Parasitol. Res. 84, 408-416.

Kuboki, N., Inoue, N., Sakurai, T., Di Cello, F., Grab, D.J., Suzuki, H., Sugimoto, C., Igarashi, I., 2003. Loop-mediated isothermal amplification (LAMP) for detection of African trypanosomes. J. Clin. Microbiol. 38, 2778-2780.

Medley, G.F., Perry, B.D., Young, A.S., 1993. Preliminary analysis of the transmission dynamics of $T$. parva in Eastern Africa. Parasitology 106, 251-264.

Mori, Y., Nagamine, K., Tomita, N., Notomi, T., 2001. Detection of loop-mediated isothermal reaction by turbidity derived from magnesium pyrophosphate formation. Biochem. Biophys. Res. Commun. 289, 150-154.

Mori, Y., Kitao, M., Tomita, N., Notomi, T., 2004. Real-time turbidimetry of LAMP reaction for quantifying template DNA. J. Biochem. Biophys. Methods 59, 145157.

Musoke, A., Rowlands, J., Nene, V., Nyanjui, J., Katende, J., Spooner, P., Mwaura, S., Odongo, D., Nkonge, C., Mbogo, S., Bishop, R., Morzaria, S., 2005. Subunit vaccine based on the p67 major surface protein of Theileria parva sporozoites reduces severity of infection derived from field tick challenge. Vaccine 23, 3084-3095.

Njiru, Z.K., Mikosza, A.S., Matovu, E., Enyaru, J.C., Ouma, J.O., Kibona, S.N., Thompson, R.C., Ndungu, J.M., 2008. African trypanosomiasis: sensitive and rapid detection of subgenus Trypanozoon by loop-mediated isothermal amplification (LAMP) of parasite DNA. Int. J. Parasitol. 38, 589-599.

Notomi, T., Okayama, H., Masubuchi, H., Yonekawa, T., Watanabe, K., Amino, N., Hase, T., 2000. Loop-mediated isothermal amplification of DNA. Nucleic Acids Res. E28, I-VII.

OIE, 2008. Manual for Diagnostic Tests and Vaccines for Terrestrial Animals, vols. 12, sixth ed. Office International Des Epizooties, Paris.

Poon, L.L.M., Wong, B.W.Y., Ma, E.H.T., Chan, K.H., Chow, L.M.C., Abeyewickreme, W., Tangpukdee, N., Yuen, K.W., Guan, Y., Looareesuwan, S., Malik Peiris, J.S., 2006. Sensitive and inexpensive molecular test for Falciparum Malaria: detecting Plasmodium falciparum DNA directly from heat-treated blood by loop-mediated isothermal amplification. Clin. Chem. 52, 303-306.

Qiao, Y.-M., Guo, Y.-C., Zhang, X.-E., Zhou, Y.-F., Zhang, Z.-P., Wei, H.-P., Yang, R.-F., Wang, D.-B., 2007. Loop-mediated isothermal amplification for rapid detection of Bacillus anthracis spores. Biotech. Lett. 29, 1939-1946.

Salih, D.A., Liu, Z, Bakheit, M.A., Ali, A.M., El Hussein, A.M., Unger, H., Viljoen, G. Seitzer, U., Ahmed, J.S., 2008. Development and evaluation of a loop-mediated isothermal amplification method for diagnosis of tropical theileriosis. Transbound. Emerg. Dis. 55, 238-243.

Sambrook, J., Russell, D.W., 2001. Preparation and analysis of eukaryotic genomic DNA. In: Sambrook, J., Russell, D.W. (Eds.), Molecular Cloning. Cold Spring Harbor Laboratory Press, New York, pp. 6.1-6.30.

Skilton, R.A., Bishop, R.P., Wells, C.W., Spooner, P.R., Gobright, E., Nkonge, C., Musoke, A.J., Macklin, M., Iams, K.P., 1998. Cloning and characterization of a $150 \mathrm{kDa}$ microsphere antigen of Theileria parva that is immunologically crossreactive with the polymorphic immunodominant molecule (PIM). Parasitology 117, 321-330.

Skilton, R., Bishop, R., Katende, J.M., Mwaura, S., Morzaria, S.P., 2002. The persistence of Theileria parva infection in cattle immunized using two stocks which differ in their ability to induce a carrier state: analysis using novel blood spot PCR assay. Parasitology 124, 265-276.

Thekisoe, O.M.M., Omolo, J.D., Swai, E.S., Hayashida, K., Zhang, J., Sugimoto, C., Inoue, N., 2007. Preliminary application and evaluation of loop-mediated isothermal amplification (LAMP) for detection of bovine theileriosis and trypanosomosis in Tanzania. Onderstepoort J. Vet. Res. 74, 339-342.

Thekisoe, O.M.M., Bazie, R.S.B., Coronel-Servian, A.M., Sugimoto, C., Kawazu, S., Inoue, N., 2009. Stability of loop-mediated isothermal amplification (LAMP) reagents and its amplification efficiency on crude trypanosome DNA templates. J. Vet. Med. Sci. 71, 471-475.

Tomita, N., Mori, Y., Kanda, H., Notomi, T., 2008. Loop-mediated isothermal amplification (LAMP) of gene sequences and simple visual detection of products. Nat. Protoc. 3, 877-882.

Toye, P.G., Metzelaar, M.J., Wijngaard, P.L.J., Nene, V., Iams, K., Roose, J., Nyanjui, J.K., Gobright, E., Musoke, A.J., Clevers, H.C., 1995. Characterization of the gene encoding the polymorphic immunodominant molecule, a neutralizing antigen of Theileria parva. J. Immunol. 155, 1370-1381.

Toye, P.G., Nyanjui, J., Goddeeris, B., Musoke, A.J., 1996. Identification of neutralization and diagnostic epitopes on PIM, the polymorphic immunodominant molecule of Theileria parva. Infect. Immun. 64, 1832-1838. 